OUTSTANDING

FUNCTIONALITY

AND COMFORT

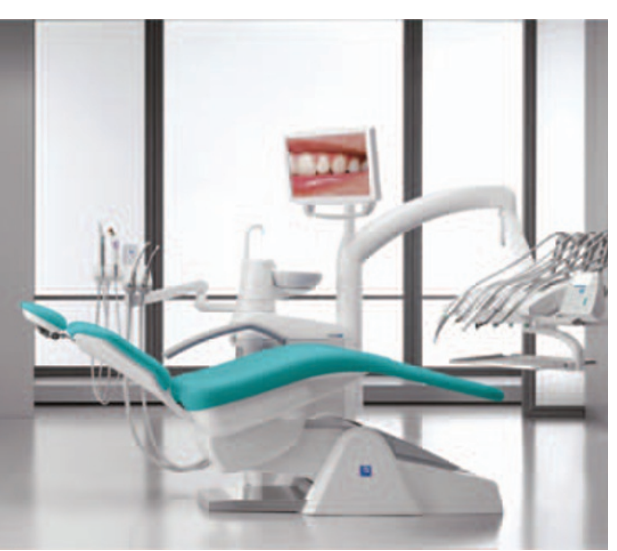

With clean, simple, modern designs and cutting edge technology, Stern Weber dental units from Clark Dental provide exceptional patient comfort and outstanding functionality.

Stern Weber dental units are made using state-of-theart materials with flexible co-moulded polyurethane upholstery for increased wear resistance and easy cleaning. All units include numerous points of adjustability, including chair height, headrests and footrests, to optimally position the patient and reduce obstructions to the dentist's movements. Stern Weber chairs also feature an ergonomically efficient design for superior comfort.

The highly manoeuvrable dentist and assistant modules provide a vast array of essential instruments and specific optional extras, dependent on your surgical requirements. With an almost unlimited combination of practical instrument positions, Stern Weber units offer a comprehensive solution to any chairside requirements.

Call Clark Dental today on 01268733146 for details on their new rental option with no deposit, nothing to pay for six months, big tax savings and a five year upgrade at the same price. Visit them online at www.clarkdental.co.uk.

\section{UPDATES YOUR CPD WITH THE GDC}

Designed specifically for dental professionals in the UK, the all new CPD Pro app can be used on your iPhone, iPad or personal computer. CPD Pro automatically updates your CPD activity with the GDC, so there's no need for any more filing or paperwork. CPD Pro takes care of everything for you.

To record CPD, take a photograph of the certificate with your smartphone and CPD Pro automatically updates your CPD database. Or download a study module direct to your device. These include core subjects and can be completed at home, during breaks or even the middle of the night - whatever works for you.

CPD Pro keeps your record backed up online so you'll never lose it.
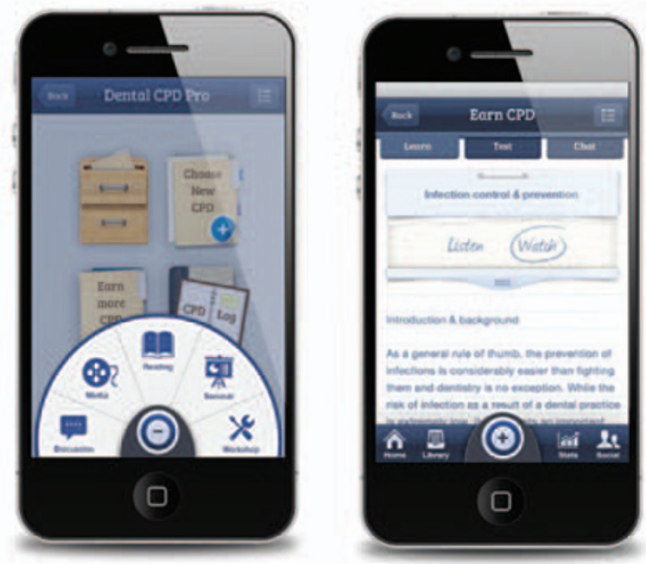

The app is currently free to download but there are limited spaces.

For more information visit the Dental CPD Pro website at http://dental.cpdpro.org.uk.

\title{
TRUST THE MASTER WITH YOUR WEBSITE
}

Make your practice stand out from the crowd with a website from Dental Focus web design. With over 500 dental websites already to their name, the team at Dental Focus are widely regarded as the trusted experts in dental website design and have a number of industry awards to their name.

Guided by Internet Marketing Director Krishan Joshi aka 'the Master', the Dental Focus web team have all the skills and experience to make your website stand out and convert patients to your practice. Not only can the Dental Focus internet superheroes guide and advise you on all aspects of search engine optimisation (SEO), but they can also show you how to put your practice on the Google map and gain the best exposure through social media platforms such as Facebook and Twitter.

With the experienced Dental Focus web design team at your side, you can be sure your practice is in good hands.

For more information call 02071838388 or visit www.dentalfocus.com.

\section{PROCURE YOUR OWN PUMA}

Castellini's Puma ELI 5 Cart dental unit gives dental professionals advanced technology and aesthetically pleasing design, while saving space in dental surgeries through its Dental Cart Delivery module.

Regulatory requirements for a dedicated LDU decontamination room in UK dental surgeries can make it yet more difficult for a substantial number of clinicians working in cramped ex-residential premises to operate with the necessary degree of efficiency and comfort.

The ELI 5 Cart allows dentists and their staff an extraordinary degree of flexibility during procedures. The hanging tubes and vertically adjustable instrument module mean that the unit's users can always avoid excessive physical strain in any treatment situation. The Integrated Cart module connected by one multifunctional foot control makes the disinfection and decontamination process automatic, both enhancing productivity and ensuring a failsafe cleaning process

For the highest level of convenience and adaptability in your dental units, choose the Castellini Puma ELI 5 Cart.

Call Castellini UK Ltd on 08000933975 for details of your local Castellini dealer.

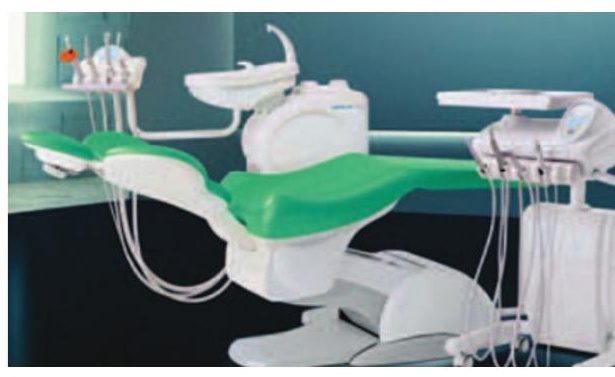

